\title{
TRIANGULATION IN SOCIAL WORK RESEARCH: THE THEORY AND EXAMPLES OF ITS PRACTICAL APPLICATION
}

\section{Mike Weyers, Herman Strydom \& Arnel Huisamen}

\section{INTRODUCTION}

The social work researcher is often faced with the daunting task of having to analyse complex phenomena and systems or relationships without the luxury of an abundant supply of resources, time and standardised measuring instruments. A typical response has been attempts to follow either the qualitative or quantitative research routes stringently, only to find that the final result did not meet scientific requirements. This has necessitated a rethink of the predominant way in which social work research is conducted in South Africa and to find a route that would meet both the demands of science and accommodate the constraints of research practice. One such route is the use of triangulation.

In this exploration four core topics will be discussed. They are the nature and the types of triangulation that could be used, as well as its advantages and disadvantages. This will be followed by a practical illustration of how triangulation was utilised in a research project undertaken by Police Social Work Services.

\section{THE NATURE OF TRIANGULATION}

The principles involved in triangulation can be traced back to ancient times, when the discovery was made that it was possible to locate or fix an object's exact location with the use of multiple reverence points. It soon became a core tool in navigation and military strategy, and to this day it forms a cornerstone of the surveyor's trade (Jick, 1983:136; Neuman, 2003:137). Although the original Greek word implied that it consisted of the "making of a triangle", triangulation does not actually require the use of three reference points or options, only more than one (Denzin, 1989:234; Rubin \& Babbie, 2001:334-335).

Although the idea of utilising triangulation in the social and behavioural sciences originated in the 1950s (Hakim, 1987:63,144), it has still not become standard practice, in spite of its advantages. This is probably due to the fact that it can take on a wide variety of forms and can become very complicated (Bryman, 2003:4-5; Ritchie \& Lewis, 2003:275). But recent experience has showed that the latter does not necessarily have to be the case.

Although there are various definitions of triangulation, it can basically be seen as the use of multiple theoretical perspectives/procedures/methods, sources of data, investigators or theories to collect and interpret data about a phenomenon in order for them to converge on an accurate representation of that particular "reality" (Brink, 2003:215; Hilton, 2003). This definition implies, inter alia, that triangulation can take on a variety of forms. Some of the most predominant of these forms or types will be briefly reviewed.

\section{DIFFERENT TYPES OF TRIANGULATION}

Triangulation can be utilised on all levels of research and can cover from micro to macro issues. In the following overview only the most predominant type of triangulation on each of these levels will be examined. 


\section{The triangulation of procedures}

One of the most common types of triangulation is the simultaneous or sequential use of more than one data-collecting technique or research procedure/method to tap different dimensions of the same phenomenon (Denzin \& Lincoln, 1994:215, 224). Such a triangulation of procedures (also known as "methodological triangulation") can take on either an "intra-method" or a "intermethod" form (Sarantakos, 2000:168). Intra-method refers to the use of two or more techniques of the same method to collect data (Bauer \& Gaskell, 2000:90). This would typically encompass the use of multiple quantitative instruments (e.g. questionnaires) to measure the same problem. In the case of the inter- or between-method, two or more procedures of different methodological origin are utilised. It would, for example, entail the use of both quantitative (e.g. questionnaires) and qualitative (e.g. interviews and focus groups) techniques (Denzin, 1989:244; Erlandson, Harris, Skipper \& Allen, 1993:138). Both methods could also be combined in one research project.

The advantage of the triangulation of different procedures lies in the fact that the flaws of one are often the strengths of another. By combining procedures/techniques, the researcher can utilise the strengths of each, while overcoming their unique deficiencies (Denzin, 1989:244). The process, however, does not imply that either the process/techniques or the data that are generated should be mixed. The results of each procedure must first be discussed separately. Only as a next step could triangulation of data be considered.

\section{The triangulation of data}

In the triangulation of data the evidence produced by different techniques or procedures is compared in order to reveal similarities and incongruencies. Typically, strong similarities could be viewed as a validation of the data or conclusions, while incongruencies would be indicative of either one or more faulty procedures or data sets. In the latter case, triangulation provides scope for the further analysis of the data or additional exploration and research.

There are also other ways in which data can be triangulated. Practitioners would, for example, routinely collect most of their information via interviews from informants and then cross-check it against some independent sources. Similarly, clients will also be provided with the opportunity to comment on the results of a completed investigation prior to the report going to court. This is sometimes referred to as "respondent validation" (Gomm, 2004:188). The same principles also apply to more "formal" types of research where, for example, survey researchers would correlate the data generated by a questionnaire with that of an independent source, or where news reports are cross-checked against official records and diaries.

\section{The triangulation of theory}

There are often multiple ways in which the same phenomenon may be interpreted (Denzin, 1989:246). Therefore, instead of opting for only one theory, the researcher may decide to use multiple theories or perspectives in the interpretation of the same set of data. This is called the "triangulation of theory" or "theory triangulation". An example would be the combined use of the assumptions and concepts from conflict theory and exchange theory as an interpretation mechanism (Neuman, 2003:138-139).

\section{The triangulation of paradigms}

One of the most often used types of triangulation is that of paradigms. In this construct a "paradigm" refers to the qualitative and quantitative styles of research. Studies that combine and cross-tabulate qualitative and quantitative data tend to be more comprehensive (Neuman, 
2003:139), better able to utilise such data sets different but complementary strengths (De Vos, 2005:360-361; Jick, 1983:135) and more likely to look at something from several angles instead of only one (Neuman, 2003:138).

\section{Investigator triangulation}

In the case of investigator triangulation, a team of researchers from the same or different disciplines is mobilised to study the same phenomenon. Such a team could bring a diversity of expertise and perspectives to a study and, in this way, counter the bias that often comes from a single person doing all the data collection and interpretation (Denzin, 1989:239; Neuman, 2003:138). When multiple researchers, evaluators and/or observers are used, not all of them have to occupy equally prominent roles in the actual process (Denzin \& Lincoln, 1994:215).

\section{Interdisciplinary triangulation}

Interdisciplinary triangulation can be viewed as a variation on investigator triangulation. In this case a deliberate attempt is made to mobilise representatives from different disciplines in order to inform the research process, to broaden the understanding of a phenomenon and to reveal different perspectives about its nature (Denzin \& Lincoln, 1994:215; Rubin \& Babbie, 2001:432). A typical example of such an endeavour was the Second Carnegie Inquiry into Poverty in South Africa (Wilson \& Ramphele, 1989).

\section{THE ADVANTAGES AND DISADVANTAGES OF TRIANGULATION}

Triangulation is predicated on a simple idea, viz. that several observations of a phenomenon are better than only one (Bechhofer \& Paterson, 2000:57). This has several advantages, but also a downside.

\section{The advantages of triangulation}

The advantages of triangulation can be divided into three broad categories. They entail an increase in the comprehensiveness and completeness of the research, an enhanced ability to confirm trends and identify inconsistencies and an improvement in the reliability and validity of findings.

\section{Increase comprehensiveness and completeness}

If a multi-method approach is followed, it will produce a variety of information from multiple perspectives on the same issue and, in so doing, enrich the understanding of the deeper and varied dimensions of the given phenomenon (Jick, 1983:138; Patton, 2002:247; Silverman, 2000:99). It will also increase the trustworthiness, persuasiveness and quality of the findings by countering any concern that a study's results are simply the product of working in a singular fashion (Bryman, 2003:1; Erlandson et al., 1993:137; Jick, 1983:145; Patton, 2002:563; Tutty, Rothery \& Grinnell, 1996:113). The objective is, however, not only that different sources should produce confirmatory data. It is also that each would contribute an additional piece of the puzzle and in so doing contribute to a more comprehensive and complete picture (D'Cruz \& Jones, 2004:76; Hilton, 2003:2).

\section{Confirm trends and identify inconsistencies}

The single-method, single-theory, single-investigator, single-site and/or single unit of analysis types of studies often suffer from intrinsic deficiencies. These include a lack of the different data sets that would enable the researcher to draw comparisons, (re-)confirm trends, identify inconsistencies and uncover the deviant dimensions of a phenomenon (Hesse-Biber \& Leavy, 
2006:168; Hilton, 2003:2; Jick, 1983:145). Triangulation does not have these deficiencies and is less biased.

\section{Improves reliability and validity}

It is generally accepted that the reliability and validity of any study would improve if the researcher uses several different types of sources that provide more insight in the same event/relationships and then cross-check the result against that of another procedure (Babbie \& Mouton, 2001:275; De Vos, 2005:361-362; Monette, Sullivan \& DeJong, 2002:456; Patton, 2002:306; Silverman, 2000:98-99). A multi-method approach would also compensate for the inherent deficiencies of single methods and contribute to a more valid end result (Babbie, 2004:113; Denzin, 1989:236; Mouton, 1998:156-157; Sarantakos, 2000:169). Through triangulation it can also be ascertained whether measuring instruments were indeed measuring what they were supposed to measure and whether they remain constant over time (Walliman, 2006:34).

\section{The disadvantages of triangulation}

In spite of its important advantages, triangulation also has various disadvantages. These can be clustered into three categories.

\section{They tend to be more costly and demanding}

Triangulation is a time-consuming process and, because it usually requires more data collectors and data preparation, quite expensive. It also demands that the researcher should have expertise in each of the research methods that are used. If qualitative and quantitative procedures are combined, the analysis becomes even more difficult because both numerical and contextual/linguistic data will have to be interpreted and then compared.

\section{They tend to generate masses of data and meanings}

The convergence gained through triangulation never results in data reduction, but rather in the proliferation of meanings that are brought about by different vantage points (Erlandson et al., 1993:139). Approaching a situation from two or more perspectives, methods, theories or paradigms often produces contradictions, because social phenomena tend to look different from different angles (Bauer \& Gaskell, 2000:345).

\section{They do not necessarily produce better results}

The findings of studies based on several procedures are not necessarily of a higher quality nor do they automatically produce a more complete picture than those based on a single-method (Sarantakos, 2000:169; Silverman, 2000:99). Jick (1983:146) states that if the research is not clearly focused theoretically, all the methods in the world will not produce a satisfactory outcome.

The demands that triangulation place on the researcher and research process have had a restricting effect on its widespread use in social work research. There is, however, ample proof that the researcher does not necessarily have to trade in his/her ideal of a high-level scientific endeavour for something else, purely because of the latter's ease of use. Various examples of how this can be achieved are found in a research project that was undertaken by Huisamen and Weyers (2005:50-94).

\section{EXAMPLES OF THE PRACTICAL APPLICATION OF TRIANGULATION}

The examples of the practical application of triangulation that are provided here will be drawn from a research project into the effect of the HIV/AIDS Awareness Module that is presented by 
Police Social Work Services to SAPS recruits. The overview will focus on the background and nature of this specific module and especially how triangulation was integrated into the research procedure and the interpretation of results.

\section{Background and nature of the HIV/AIDS Awareness Module}

The South African Police Service (SAPS) introduced a new Self-Management Programme into its basic training programme for recruits in July 2004. It was developed by Police Social Work Services (PSWS) and consisted of nine separate modules, viz.: "Be Money Wise", "Planning of Goals", "Self-Knowledge", "Conflict Management", "Assertiveness", "Problem-Solving", "Stress Management", "Substance Dependency" and "HIV/AIDS Awareness" (Huisamen \& Weyers, 2005:15). Its combined ultimate aim was to enhance the recruits' resilience and professional conduct as police officials (Huisamen \& Weyers, 2005:22).

All the modules can be typified as structured personnel capacity-building interventions. They are similar to interventions that are sometimes referred to as psychosocial education, life-skills training, human resource development, and personal or social education programmes (NelsonJones, 1991:23; Rooth, 2000:34; Williams \& Weyers, 2006:19). Each module is presented in a workshop format in which extensive use is made of experiential learning methods. One presenter/facilitator (a social worker) is assigned to each platoon of between 28 to 36 recruits and is responsible for presenting the complete programme.

The HIV/AIDS Awareness Module is the last of the nine modules that are presented and has a time allocation of 8 contact hours. It pursues three core outcomes. They are to increase the recruits' knowledge of HIV/AIDS and associated issues, to change their attitude towards the disease and to secure a personal commitment from them to reduce their own risk of becoming infected (Huisamen \& Weyers, 2005:19). In order to achieve this result, six main themes are covered. They are:

- The nature of/defining HIV and its impact;

- HIV prevention;

- Substance abuse, HIV and STIs;

- HIV-risk assessment and prevention strategies;

- Voluntary counselling and testing;

- Review of HIV prevention and behaviour change issues (Huisamen \& Weyers, 2005:36).

\section{The research design and procedure}

In 2004 a start was made with a comprehensive study into the module's effect. In a process that could be typified as the "triangulation of procedures", an experimental design was utilised to quantify the module's short-term effect. This was followed by the use of a more qualitative and descriptive design in which focus groups were used to ascertain its long-term effect.

The research procedure consisted of five basic steps. They were a literature study, the design and testing of the measurement instruments, the measurement of the modules' short-term and longterm effects, and the analysis and triangulation of all the research data.

The results of a comprehensive literature study were, inter alia, used to design concept datagenerating instruments. These were evaluated by a panel of five experts and then pilot tested. The pilot study took place in July 2004 and involved 130 respondents from the Oudtshoorn and Pretoria Basic Training Provision Institutions (BTPIs). The data generated by this process were subjected to a thorough statistical analysis and the results used to improve the instruments. 
The first phase of the main study lasted from 24 to 29 January 2005 . It consisted of the selection and mobilisation of the various experimental groups, their completion of the different pre-tests, the presentation of the modules (independent variable) to them, and then their completion of the post-tests as well as a presentation evaluation questionnaires. At the same time different control groups completed similar pre-test and post-test questionnaires without taking part in the modules. The triangulation of the data sets made it possible to calculate the net effect of the modules on the experimental group.

The second phase commenced at the end of July 2005 (i.e. six months after the first phase) and consisted of various focus group sessions with student constables. The main aim of these sessions was to ascertain the long-term effect of the modules on their work and personal functioning.

All the data generated by the research were then analysed and triangulated.

\section{The participants}

The participants in the main phase of the research were divided into four groups. These were the members of the experimental groups, the control groups, the focus group members and the social workers who presented the module.

The experimental group consisted of 378 participants, who were selected on a stratified random basis (Strydom, 2005:200) from the more southerly Oudtshoorn, the more easterly Bisho and the more northerly Pretoria Basic Training Provision Institutions (BTPIs). The 121 control group members were selected on the same basis, but from the Phillipi, Graaff-Reinet and Chatsworth BTPIs. All the groups completed the questionnaires at the same time. The social workers who presented the module to the experimental groups were also requested to complete a presenter's evaluation questionnaire.

Two focus groups, consisting of a total of 24 recruits from Plettenberg Bay and Pretoria Central, were mobilised seven months after the completion of the module. This selection was done on an availability basis.

\section{The measurement instruments}

Four categories of instruments were used during the study. They were:

- a knowledge, attitudes and behavioural (KAB) questionnaire;

- a presentation evaluation questionnaire;

- a presenter's evaluation questionnaire; and

- a focus group schedule.

The questionnaires mostly consisted of multiple scales. Due to the uniqueness of the HIV/AIDS Awareness Module, it was not possible to utilise standardised instruments. Completely new ones had to be developed. It was originally expected that this might not prove to be entirely successful and provision was consequently made for the triangulation of all data. Such a step would also enhance the validity and comprehensiveness of the measurements. All the scales did, however, have an excellent reliability coefficient and were able to measure change effectively.

The quantitative part of the study utilised the "intra-method" (Sarantakos, 1998:186) or "within method" (Bryman, 2003) of triangulation. It specifically entailed the use of multiple instruments to measure the same phenomenon, viz. the change that the module brought about (Mark, 1996:220; Patton, 2002:556, 559-560). Its purpose was "to capture a more complete, holistic and 
contextual portrayal and reveal the varied dimensions of a given phenomenon" (Hilton, 2003) and, at the same time, test the constancy of measurement (Patton, 2002:248).

The intra-method type of triangulation was primarily done by first analysing the results obtained though the use of eight individual scales and the focus group schedule and then drawing comparisons between these results ("The triangulation of procedure"). Five of the scales were contained in the KAB questionnaire and completed on a pre-test and post-test basis by both the experimental and control groups. A value scale (Scale 6) and a relevance scale (Scale 7) were added to the post-test $\mathrm{KAB}$ questionnaire of the experimental group and they also completed a presentation evaluation questionnaire (Scale 8). The presenting social workers had to complete a separate presenter's evaluation questionnaire. The quantitative data that were produced by all of the scales were triangulated with each other and also with the qualitative data produced by the focus groups. The manner in which this was done is portrayed in Diagram 1.

\section{DIAGRAM 1 \\ THE TRIANGULATION OF PROCEDURE IN THE HIV/AIDS AWARENESS STUDY}

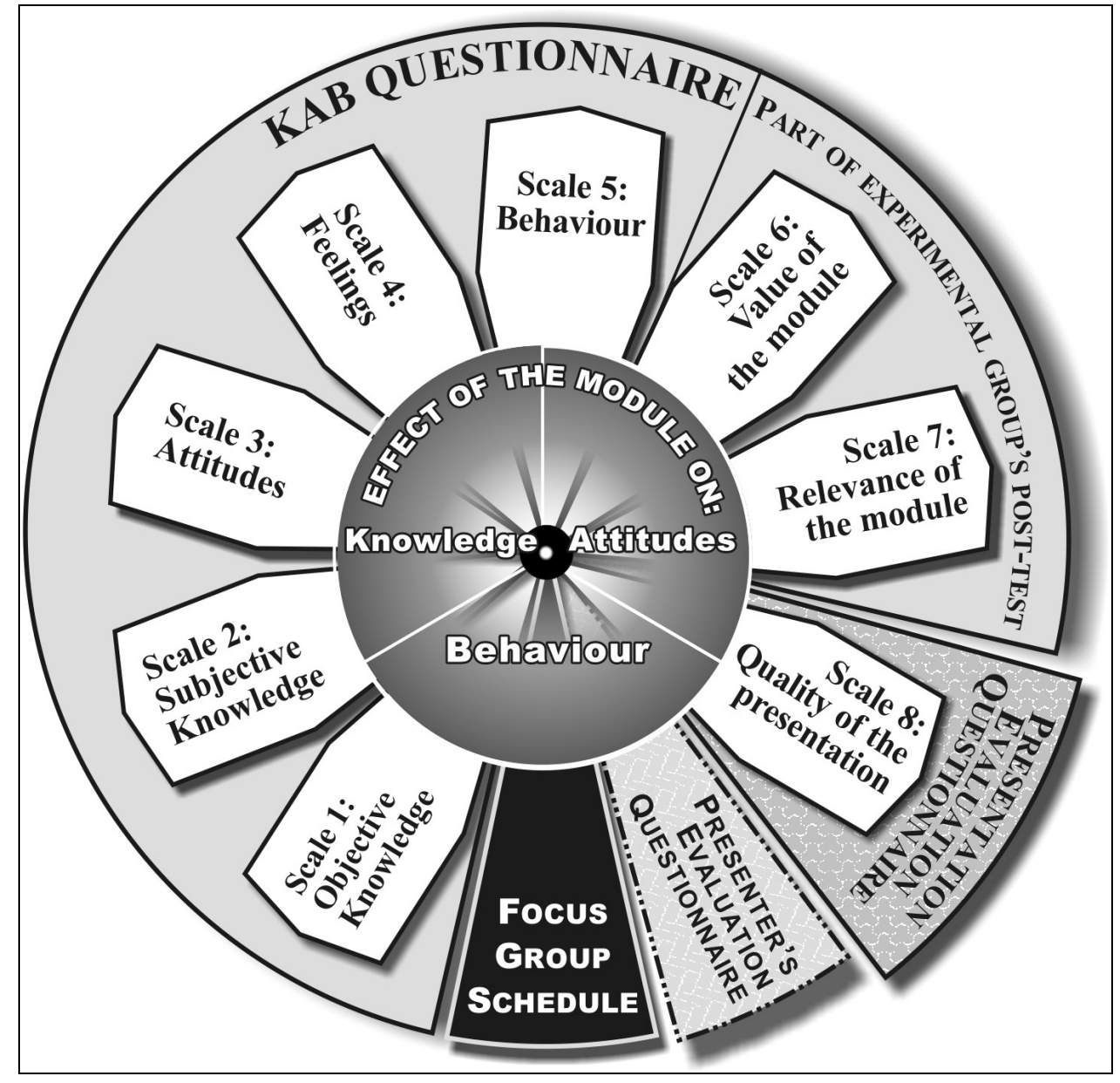

\section{Formulas used in data analyses}

All the quantitative data were analysed in conjunction with the Statistical Consultation Services of the North-West University, Potchefstroom Campus, and with the aid of the SAS computer package (SAS Institute Inc, 1999). It included the calculation of each scale's Cronbach alpha coefficient (" $\alpha$ ") in order to determine its reliability (Gravetter \& Forzano, 2003:455). A score of 0,5 or higher was accepted as an appropriate reliability coefficient (Jackson, 2003:87-91). All the scales complied with this minimum criterion. 


\section{4}

In order to measure whether a practical significant change was brought about by the intervention, use was made of Cohen's formula for the calculation of effect size (i.e. "d-value"). This formula is as follows:

$$
d=\frac{\left|\mu_{1}-\mu_{2}\right|}{\sqrt{M S E}}
$$

Where:

$$
\begin{array}{lll}
D & = & \text { effect size } \\
\mu_{1} & = & \text { average difference score in the experimental group (e) } \\
\mu_{2} & = & \text { average difference score in the control group (c) } \\
\mu_{1}-\mu_{2} & = & \text { difference between average difference } \\
M S E & = & \text { mean square error of the ANCOVA } \\
& & \text { (Cohen, 1988:20-27; Steyn, 2000:1-3). }
\end{array}
$$

The following guidelines can be used to judge all d-values:

- $d=0.2$ : This indicates a small effect, implying that the research should be repeated in order to confirm if there is an effect;

- $d=0.5$ : This indicates a medium effect, implying that the result can be viewed as significant, but also that better planned research could produce even more significant results;

- $d=0.8$ : This indicates a large effect which is significant and of practical significance;

- Because there are no absolute boundaries between the three d-values, concepts such as "small to medium effect" and "large effect" can be used (Cohen, 1969:22-25; Spatz, 2001:74-75; Steyn, 1999:3).

Besides effect sizes (d-value), use was also made of certain scales and questions of descriptive statistics such as totals, percentages and averages.

\section{THE EFFECT OF THE MODULE ON PARTICIPANTS' KNOWLEDGE, ATTITUDES AND BEHAVIOUR}

The purpose of the HIV/AIDS Awareness Module is not only to increase the recruits' knowledge of the disease, but also to change their attitude towards the syndrome and especially their short-term and long-term AIDS-related behaviour (PSWS, 2002:6). To ascertain to what extent these goals were achieved, the individual effect measurements (see Table 1) were analysed and then triangulated with the results of the focus group sessions. Only the most salient results from this first form of triangulation that was used in the study will be covered.

\section{TABLE 1}

THE COVARIANCE ANALYSIS FOR SCALES 1-4: HIV/AIDS AWARENESS MODULE

\begin{tabular}{|l|ccccc|}
\hline \multicolumn{1}{|c|}{ Scale } & $\mathbf{n}$ & $\begin{array}{c}\text { Difference in } \\
\text { averages }\end{array}$ & $\sqrt{ }$ MSE & p- Value & d- Value \\
\hline Scale 1: Objective knowledge & 496 & 0,491 & 0,606 & $<, 0001$ & $0,81^{* *}$ \\
Scale 2: Subjective knowledge & 499 & 1,102 & 0,399 & $<, 0001$ & $2,76^{* *}$ \\
Scale 3: Attitudes & 499 & 0,276 & 0,3 & $<, 0001$ & $0,92^{* *}$ \\
Scale 4: Feelings & 492 & 0,311 & 0,273 & $<, 0001$ & $1,14^{* *}$ \\
\hline Scale 5: (Intended) Behaviour & 495 & 0,652 & 0,275 & $<, 0001$ & $2,36^{* *}$ \\
\hline
\end{tabular}

* Medium effect: $\mathrm{d} \leq 0.5 * *$ Practical significant effect: $\mathrm{d} \geq 0.8$ 
In the research changes in both so-called "objective" and "subjective" knowledge were measured. "Objective knowledge" referred to the participants' actual comprehension of the facts regarding a certain subject that can be measured by means of typical true/false questions. "Subjective knowledge", on the other hand, refers to their subjective perception of the extent to which they had mastered the subject matter (Jarvis, 1990:323).

\section{An increase in objective knowledge}

The module produced an unexpectedly large increase in recruits' knowledge of HIV/AIDS and related issues. The reason that this increase was unexpected was because it is generally accepted that the South African public has been thoroughly educated in this regard during their school training and through the media. The practical significant d-value of 0,81 , together with other research data, indicated that this was not the case as far as the recruits were concerned.

From the focus group sessions it became clear that this increase in knowledge was not of a shortterm nature. Even after six months they could still verbalise their new found knowledge on, for example, the differences between HIV/AIDS facts and myths, the correct use of male and female condoms, and HIV transmission from mother to child.

\section{An increase in subjective knowledge}

The d-value of 2,76 (Table 1) indicates that the recruits were convinced that the module successfully empowered them with new HIV/AIDS-related knowledge. This perception was still evident after six months.

The reasons for the increases in objective and subjective knowledge are probably due to the content and focus of the module. Instead of only focusing on the physiological dimension of the disease, it also deals in some depth with issues such as practical prevention strategies, factors that contribute to high-risk behaviour and voluntary counselling and testing. This enables participants to make informed decisions on their own lives.

\section{The change of attitudes and feelings}

The measurement of the module's effect included both an attitude and a feelings scale. The reason for this was that HIV/AIDS has become an emotion-laden issue and that changes in the nature and intensity of such emotions had to be measured (Black, 1999:215).

Both Scales 3 and 4 produced a practical significant d-value of above 0,8 (Table 1). There was, however, a marked difference between that for attitudes $(\mathrm{d}=0,92)$ and feelings $(\mathrm{d}=1,14)$. The probable reason was that Scale 3 mostly dealt with attitudes towards external systems (e.g. HIVpositive people), while the latter focused on the participant's personal feelings regarding, for example, the use of condoms.

The focus groups indicated that the changes in attitudes and feelings were not only a short-term phenomenon. Even after six months their attitudes towards HIV-positive people and feelings regarding the use of condoms and HIV testing remained positive. It was also obvious that they were more aware of developments in the AIDS field and its influence on society, as well as their personal responsibility to do something about it.

\section{The change of behaviour}

Because the behaviour scale was administered shortly after the completion of the module, it could not measure behavioural change directly. It therefore focused on how the participants intended to change their behaviour in future (McCormack \& Hill, 1997:69). The very high and 
practical significant d-value of 2,36 (Table 1) indicated that it succeeded admirably in this primary goal.

It was, however, an open question whether the recruits' intentions would translate into actual behavioural change. Consequently a special attempt was made to find the answer during the focus group sessions. From the sessions it became clear that this was indeed the case. Participants, for example, indicated that they will now think twice before engaging in risky sexual behaviour, that they now always use a condom, and that they have taken it upon themselves to warn others of the dangers of AIDS and the risks involved in unprotected sex.

\section{The long-term effect of the module}

The focus group sessions were structured according to the six main themes that were covered in the original module. The discussions especially focused the participants' current levels of knowledge, attitudes, feelings and behaviour, and the drawing of comparisons between this profile and the state of affairs that existed before the commencement of the module. Some of the main findings were that the intervention had an especially strong long-term effect on their behaviour and attitudes. They were, for example, taking proactive steps to prevent HIV infection and maintained their changed attitudes towards the disease and HIV-positive people.

\section{THE VALUE OF THE MODULE}

Triangulation was, secondly, applied by comparing the results of the value scale (Scale 6) with those of the KAB scales and focus groups.

The value scale enabled respondents to evaluate each component of the module, as well as the module as a whole. An average of $86,2 \%$ indicated that the module and its components were of exceptionally high value and another $13,49 \%$ indicated that it was "very valuable". Less than $1 \%$ placed it in one of the below average categories (Huisamen \& Weyers, 2005:83). Because the module was intended to increase participants' knowledge and change their attitudes and (intended) behaviour, this result indicated that it succeeded in bringing about significant changes on all three levels.

The results of the value scale can be seen as a reaffirmation of the results achieved with the KAB scales. When these two data sets were triangulated, it became clear that the lower (albeit significant) d-value that was achieved with Scale 1 was more due to the choice of inappropriate questions than a lower impact. All the other indicators, including the results of the focus group sessions, showed that it brought about a very significant increase in knowledge.

\section{THE RELEVANCE OF THE MODULE}

The third form of triangulation dealt with the participants' view of the relevance of the module. This type of measurement was included because a module may be of value to participants, but if compared to other programmes, would not be seen as a priority. The core question that had to be answered was whether the module made a significant contribution to the effective functioning of a student constable as an individual and as an employee.

The measurement produced the same type of response as the reaction shown to the value of the module. In total $99.67 \%$ of the respondents were of the opinion that it was relevant or highly relevant to themselves as individuals as well as personnel of the SAPS in general (Huisamen \& Weyers, 2005:83). 
When, fourthly, the results of all seven scales and the focus group sessions were triangulated, it was clear that the module succeeded exceptionally well in achieving its purpose. It changed the participants' short-term and long-term knowledge levels, attitudes, feelings and behaviour in a significant manner and was viewed as highly relevant and valuable by the vast majority. This was the singular most important result of the whole study.

\section{THE INFLUENCE OF THE MODULE PRESENTATION}

The HIV/AIDS Awareness Module is presented across South Africa by a large number of different SAPS social workers. It was, consequently, important to ascertain what influences the quality of these presentations had on the effect of the module. By triangulating these results with those of the effect measurements, it would also be possible to identify similarities and incongruencies. Strong similarities would validate the data or conclusions, and incongruencies would necessitate further analysis of the data or even additional research.

The influence of the module presentation was measured with Scale 8. It consisted of four subscales that dealt with the four important facets of a presentation. Sub-scales 8.1 and 8.2 covered the presenter's expertise and presentation skills. The reason for this focus was Rooth's (2000:89) view that the presenter/facilitator plays a pivotal role in the success of any educational or capacity-building programme. Sub-scale 8.3 focused on the quality of the learning process. It attempted, amongst other things, to ascertain whether the most appropriate didactic procedure was followed, if the learning material was clear and useful, and if the communication was on the participants' level. With sub-scale 8.4, attendees were provided with the opportunity to evaluate the context within which the presentation took place. It dealt with issues such as the quality of the venue, how well the programme was organised and the quality of the educational aids. The reason for this focus was that the quality of these "environmental" factors could have a direct effect on the whole learning process (Nelson-Jones, 1991:60).

The questionnaire also had a general section that included the evaluation of the length of the programme, the tempo of the presentation and the extent to which a balance was maintained between the presentations and group participation.

The data produced by these subscales are summarised in Table 2 on the next page. Because it was only a post-test, averages per scale had to be used.

Table 2 shows that, according to the recruits, the social workers presented the module in an effective and professional way. They were especially impressed with the presenters' presentation skills, preparation and ability to facilitate the small group processes. Any deficiencies in the module could, as a result of these and other findings, not be attributed to the presenters.

The presentation context received the lowest rating of all four the dimensions. This was because some of the venues, as well as the quality of some learning material and tools, were not up to standard. Because an average of $74,91 \%$ of the participants still described these issues as "very good" (Table 2), they should not necessarily be viewed as problematic. None of the other issues such as the tempo of the presentation or the balance between group participation and presentations showed any negative trends. 
TABLE 2

SCALE 8: EVALUATION OF THE MODULE PRESENTATION

\begin{tabular}{|c|c|c|c|c|c|c|}
\hline \multirow[t]{2}{*}{ Sub-scale } & \multirow[t]{2}{*}{$\mathbf{n}$} & \multicolumn{5}{|c|}{ Evaluation of the module presentation } \\
\hline & & \multicolumn{2}{|c|}{$\begin{array}{c}1 . \\
\text { Strongly disagree }\end{array}$} & $\begin{array}{c}2 . \\
\text { Disagree }\end{array}$ & $\begin{array}{c}3 . \\
\text { Agree } \\
\end{array}$ & $\begin{array}{c}4 . \\
\text { Strongly agree }\end{array}$ \\
\hline $\begin{array}{l}\text { Sub-scale 8.1: } \\
\text { Evaluation of the } \\
\text { presenter }\end{array}$ & 330.8 & \multicolumn{2}{|c|}{$\begin{array}{c}3.2 \\
(0.97 \%)\end{array}$} & $\begin{array}{c}3.6 \\
(1.09 \%)\end{array}$ & $\begin{array}{c}41.6 \\
(12.58 \%)\end{array}$ & $\begin{array}{c}282.4 \\
(85.37 \%)\end{array}$ \\
\hline $\begin{array}{l}\text { Sub-scale 8.2: } \\
\text { Evaluation of the } \\
\text { presenter's presentation } \\
\text { skills }\end{array}$ & 338 & \multicolumn{2}{|c|}{$\begin{array}{c}0.5 \\
(0.15 \%)\end{array}$} & $\begin{array}{c}0.25 \\
(0.07 \%)\end{array}$ & $\begin{array}{c}38.75 \\
(11.46 \%)\end{array}$ & $\begin{array}{c}298.5 \\
(88.31 \%)\end{array}$ \\
\hline $\begin{array}{l}\text { Sub-scale 8.3: } \\
\text { Evaluation of the } \\
\text { learning process }\end{array}$ & 339 & \multicolumn{2}{|c|}{$\begin{array}{c}0 \\
(0 \%)\end{array}$} & $\begin{array}{c}1.4 \\
(0.41 \%)\end{array}$ & $\begin{array}{c}53.8 \\
(15.87 \%)\end{array}$ & $\begin{array}{c}283.8 \\
(83.72 \%)\end{array}$ \\
\hline \multirow{2}{*}{$\begin{array}{l}\text { Sub-scale 8.4: } \\
\text { Evaluation of the } \\
\text { presentation context }\end{array}$} & \multirow[b]{2}{*}{338.75} & $\begin{array}{c}1 . \\
\text { Very bad }\end{array}$ & $\begin{array}{c}2 . \\
B a d\end{array}$ & $\begin{array}{c}3 . \\
\text { Average }\end{array}$ & $\begin{array}{c}4 . \\
\text { Good }\end{array}$ & $\begin{array}{c}5 . \\
\text { Very good }\end{array}$ \\
\hline & & $\begin{array}{c}0.5 \\
(0.15 \%)\end{array}$ & $\begin{array}{c}0.25 \\
(0.07 \%)\end{array}$ & $\begin{array}{c}11.25 \\
(3.32 \%)\end{array}$ & $\begin{array}{c}73 \\
(21.55 \%)\end{array}$ & $\begin{array}{c}253.75 \\
(74.91 \%)\end{array}$ \\
\hline
\end{tabular}

All the scales were reliable, i.e. $\alpha=0.5$ or higher

\section{THE PRESENTERS' EVALUATION OF THE MODULE}

The presenters were also required to complete a questionnaire similar to the presentation evaluation one completed by recruits. In this case, however, they had to evaluate their own abilities as well as the learning process and presentation context. This made it possible to crosscorrelate the two sets of data in order to identify discrepancies and pertinent strong and weak points. This process produced remarkably similar results. It could, therefore, be viewed as a validation of the two sets of findings. The triangulation did, however, show that presenters were somewhat inclined to underestimate the impact of the module and the quality of their involvement.

\section{FINDINGS OF THE STUDY}

When all the data that were produced by the study were triangulated, it was possible to come to six overarching findings.

As far as the research design and procedure are concerned, it was clear that the triangulation of procedures and data added value to the research. This did not only eliminate the risks involved in the utilisation of non-standardised measuring instruments, but also clarified the relationships that existed between different data sets and confirmed the trends that were evident in these sets. The utilisation of an experimental design also made it possible to extrapolate the findings to the total population. It could, therefore, be concluded with some degree of certainty that all the student constables would have received the same benefits from the module as the experimental groups. 
Secondly, the KAB measurements showed that the module had a practical significant short-term effect on the recruits' knowledge, attitudes and (intended) behaviour. This would have strengthened both their individual and work-related functioning.

The long-term effect of the module was ascertained with the help of focus group sessions. It showed that its effect, especially on attitudes and behaviours, was still prevalent more than six months after the initial training. As far as increases in knowledge levels were concerned, the triangulation of the numerical/quantitative data produced by the original KAB study with the linguistic/qualitative data of the focus groups proved to be a difficult task. It was concluded that this type of triangulation is not suited to the testing of changes in actual knowledge levels and that a quantitative (e.g. "true/false") retest would have been a better option.

Fourthly, it was clear that the intervention did not only have an impact on an "objective" level. The recipients' more subjective evaluation of the value and relevance of the module showed that they also felt that the module added value to their lives. The triangulation of this trend with the data produced by the focus groups indicated that this made a considerable contribution to the long-term effect of the intervention.

Finally, it was found that the presenters, presentations and learning material were of a high standard and made a positive contribution to the attainment of the module outcomes. No indication could be found in the different data sets that smaller deficiencies in the training aids (e.g. transparencies, icebreakers and activities) and training context (e.g. venues and technical aids) had any significant effect on the overall outcome of the endeavour. These issues should, nonetheless, receive further attention.

\section{CONCLUDING REMARKS}

The utilisation of triangulation in the study of the SAPS HIV/AIDS Awareness Module produced all of the benefits, as well as some of the disadvantages, of this procedure. It increased the comprehensiveness and completeness of the research, confirmed trends and improved overall reliability and validity. It also enabled the researchers to overcome the dangers involved in the utilisation of non-standardised measuring instruments. Its downside was a costly and demanding process and masses of data that had to be interpreted. The net result was, however, a much clearer picture of the short- and long-term effect of the module and more ample proof of its success than would otherwise have been the case.

In the example the different inquiry approaches and data sources mostly produced mutually supportive results. This need not be the case in all research projects where triangulation is employed. It is a common misconception to view triangulation as a test for consistency. Different kinds of data may, on the contrary, yield different results because of their sensitivity to different real-world nuances. The failure of two or more sets of results to converge may prompt new lines of inquiry relating to either the methods concerned or the phenomenon involved (Bryman, 2003:2). Inconsistencies would consequently not automatically weaken the credibility of results, but could produce deeper insight into the relationship between inquiry approaches and the phenomenon under study (Patton, 2002:556).

It should be noted that a comprehensive multi-dimensional approach and triangulation are not necessarily suitable for every study. A single-method procedure could, for example, be more cost-effective in certain circumstances. Nevertheless, triangulation has vital strengths that should be tapped more often - if not in the overall research design, then at least in the interpretation and 
correlation of the data that are generated. This will definitely enhance the quality of social work research.

\section{REFERENCES}

BABBIE, E. 2004. The practice of social research. London: Thomson Wadsworth.

BABBIE, E. \& MOUTON, J. 2001. The practice of social research. Cape Town: Oxford University Press.

BAUER, M.W. \& GASKELL, G. 2000. Qualitative researching with text, image and sound: a practical handbook. London: SAGE Publications.

BECHHOFER, F. \& PATERSON, L. 2000. Principles of research design in the social sciences. London: Routledge.

BLACK, T.R. 1999. Doing quantitative research in the social sciences: an integrated approach to research design, measurement and statistics. London: SAGE Publications..

BRINK, H.I. 2003. Fundamentals of research methodology for health care professionals. Cape Town: Juta \& Company.

BRYMAN, A.E. 2003. Triangulation. Available: http://www.referenceworld.com/sage/ socialscience/triangulation.pdf. [Rev. 19/02/2004].

COHEN, J. 1969. Statistical power analysis for the behavioral sciences. New York: Academic Press.

COHEN, J. 1988. Statistical power analysis for the behavioral sciences $\left(2^{\text {nd }}\right.$ ed $)$. Hillsdale, N.J.: Erlbaum.

D'CRUZ, H. \& JONES, M. 2004. Social work research: ethical and political contexts. London: SAGE Publications.

DENZIN, N.K. 1989. The research act: a theoretical introduction to sociological methods. Englewood Cliffs: Prentice Hall.

DENZIN, N.K. \& LINCOLN, Y.S. 1994. Handbook of qualitative research. London: SAGE Publications.

DE VOS, A.S. 2005. Combined qualitative and quantitative approach. In: DE VOS, A.S., STRYDOM, H., FOUCHÉ, C.B. \& DELPORT, C.S.L. Research at grass roots: for the social sciences and human service professions. Pretoria: Van Schaik Publishers: 357-366.

ERLANDSON, D.A., HARRIS, E.L., SKIPPER, B.L. \& ALLEN, S.D. 1993. Doing naturalistic inquiry: a guide to methods. London: SAGE Publications.

GOMM, R. 2004. Social research methodology: a critical introduction. New York: Palgrave MacMillan.

GRAVETTER, F.J. \& FORZANO, L.B. 2003. Research methods for the behavioral sciences. Belmont (Calif.): Thomson/Wadsworth.

HAKIM, C. 1987. Research design: strategies and choices in the design of social research. London: Unwin Hyman.

HESSE-BIBER, S.N. \& LEAVY, P. 2006. Emergent methods in social research. Thousand Oaks: SAGE Publications. 
HILTON, A. 2003. Should qualitative and quantitative studies be triangulated? International Society of Nurses. Available: http://www.isncc.org/ news/triangle.htm. [Rev. 20/02/2004].

HUISAMEN, P. \& WEYERS, M.L. 2005. Die SAPD se Selfbestuursprogram: die aard en effek van die besluitnemingskomponent op student-konstabels. [The SAPS's Self-Management Programme: the nature and effect of the decision-making component on student constables.] In: HUISAMEN, P. Die effek van die besluitnemings- en lewensdoelkomponente van die SAPD se Selfbestuur Personeelkapasiteitsbouprogram. [The effect of the decision-making and purpose-in-life components of the SAPS Self-Management Programme]. Potchefstroom: NorthWest University. (PhD Thesis)

JACKSON, S.L. 2003. Research methods and statistics: a critical thinking approach. Belmont (Calif.): Thomson/Wadsworth.

JARVIS, P. 1990. An international dictionary of adult and continuing education. London: Routledge.

JICK, T.D. 1983. Mixing qualitative and quantitative methods: triangulation in action. In: VAN MAANEN, J. (ed) Qualitative methodology. London: SAGE Publications: 135-148.

MARK, R. 1996. Research made simple: a handbook for social workers. London: SAGE Publications.

McCORMACK, B. \& HILL, E. 1997. Conducting a survey: the SPSS workbook. London: Thompson.

MONETTE, D.R., SULLIVAN, T.J. \& DEJONG, C.R. 2002. Applied social research: tool for the human services. London: Harcourt College Publishers.

MOUTON, J. 1998. Understanding social research. Pretoria: Van Schaik Publishers.

NELSON-JONES, R. 1991. Lifeskills: a handbook. London: Dotesios.

NEUMAN, W.L. 2003. Social research methods: qualitative and quantitative approaches. London: Allyn and Bacon.

PATTON, M.Q. 2002. Qualitative research and evaluation methods. London: SAGE Publications.

POLICE SOCIAL WORK SERVICES see South Africa (Rep.), Police Social Work Services.

PSWS see South Africa (Rep.), Police Social Work Services.

RITCHIE, J. \& LEWIS, J. 2003. Qualitative research practice: a guide for social science students and researchers. London: SAGE Publications.

ROOTH, E. 2000. An investigation of the enhanced relationship between participants in life skills courses and the environment. Pretoria: Human Sciences Research Council.

RUBIN, A. \& BABBIE, E. 2001. Research methods for social work. London: Wadsworth Thomson Learning.

SARANTAKOS, S. 1998. Social research. South Yarra (Australia): MacMillan Education.

SARANTAKOS, S. 2000. Social research. South Yarra (Australia): MacMillan Education.

SAS INSTITUTE INC. 1999. The SAS System for Windows Release 8.02 TS Level 02M0 Copyright $@ 1999-2001$ by SAS Institute Inc., Cary, N.C.: USA. 
SILVERMAN, D. 2000. Doing qualitative research: a practical handbook. London: SAGE Publications.

SOUTH AFRICA (REP.), SOUTH AFRICAN POLICE SERVICE. 2002. HIV/AIDS Awareness Programme. Pretoria: SAPS.

SPATZ, C. 2001. Basic statistics: tales of distributions. Belmont (Calif.): Wadsworth/ Thomson Learning.

STEYN, H.S. 1999. Praktiese beduidendheid: die gebruik van effekgroottes. [Practical significance: the use of effect sizes]. (Wetenskaplike Bydraes, Reeks B: Natuurwetenskappe nr. 117). Potchefstroom: Publikasiebeheerkomitee, PU vir CHO.

STEYN, H.S. 2000. Practical significance of the difference in means. Journal of Industrial Psychology, 26(3):1-3.

STRYDOM, H. 2005. Sampling and sampling methods. In: DE VOS, A.S., STRYDOM, H., FOUCHÉ, C.B. \& DELPORT, C.S.L. Research at grass roots: for the social sciences and human service professions. Pretoria: Van Schaik Publishers: 192-204.

TUTTY, L.M., ROTHERY, M.A. \& GRINNELL, R.M. 1996. Qualitative research for social workers. London: Allyn and Bacon.

WALLIMAN, N. 2006. Social research methods. London: SAGE Publications.

WILLIAMS, H.M. \& WEYERS, M.L. 2006. The nature of the South African Police Service's Self-management Programme: with special reference to its human relations and health maintenance components. In: WILLIAMS, H.M. The effect of the human relations and health maintenance components of the SAPS Self-Management Programme. Potchefstroom: North-West University. (PhD Thesis)

WILSON, F. \& RAMPHELE, M. 1989. Uprooting poverty: the South African challenge: report for the Second Carnegie Inquiry into Poverty and Development in Southern Africa. New York: W.W. Norton.

Professor Mike Weyers, Professor Herman Strydom, Social Work Division, School for Psychosocial Behavioural Sciences, North-West University, Potchefstroom; Dr Arnel Huisamen, Police Social Work Service, SAPS, Mossel Bay, South Africa. 